\title{
SOROPREVALÊNCIA DO Toxoplasma gondii, EM SUÍNOS, BOVINOS, OVINOS E EQÜINOS, E SUA CORRELAÇÃO COM HUMANOS, FELINOS E CANINOS, ORIUNDOS DE PROPRIEDADES RURAIS DO NORTE DO PARANÁ-BRASIL ${ }^{1}$
}

\author{
SEROPREVALENCE OF Toxoplasma gondii IN SWINE, BOVINE, OVINE AND EQUINE, \\ AND THEIR CORRELATION WITH HUMAN, FELINES AND CANINES, \\ FROM FARMS IN NORTH REGION OF PARANÁ STATE, BRAZIL
}

\section{João Luis Garcia ${ }^{2}$ Italmar Teodorico Navarro ${ }^{3}$ Liza Ogawa $^{4}$ Rosângela Claret de Oliveira $^{4}$}

RESUMO

O Toxoplasma gondii, agente da toxoplasmose, encontra-se distribuído mundialmente. No presente estudo, determinou-se a prevalência do T. gondii nas espécies suína, bovina, ovina e eqüina oriundas de fazendas do município de Jaguapitã , através da imunofluorescência indireta para detecção de anticorpos da classe - IgG, considerando-se sororeagentes aqueles títulos maiores ou iguais a 1:64. Verificou-se uma prevalência de $24 \%$ em 267 amostras de suínos, 25,8\% em 400 amostras de bovinos, 51,8\% em 228 amostras de ovinos e 12,1\% em 173 amostras de eqüinos. Com relação às faixas etárias, apenas os ovinos e suínos apresentaram diferenças estatísticas significantes, aumentando a soropositividade com as idades, porém, não se verificaram diferenças estatisticamente significativas com base no sexo de nenhuma das espécies animais estudadas. Obtiveramse correlações entre os títulos de anticorpos interespécie, positivas e significativas, sendo que apresentaram importância epidemiológica aquelas entre as espécies humana-canina ( $r=0,64$ $p=0,05)$, humana-felina $(r=0,78 p=0,01)$, canina-suína $(r=0,96$ $p=0,0001)$, bovina-ovina $(r=0,82 \quad p=0,006)$, bovina-eqüina ( $r=0,89 p=0,001)$ e ovina-eqüina $(r=0,92 p=0,0004)$, demonstrando que as espécies hominívoras, carnívoras e herbívoras estariam expostas avias de transmissão comuns. Os resultados demostraram a elevada prevalência da toxoplasmose na população estudada e, conseqüentemente, o alto risco da carne como via de transmissão para o homem, quando ingerida crua ou mal cozida.

Palavras-chave: soroepidemiologia, soroprevalência, Toxoplasma gondii, suínos, bovinos, ovinos, eqüinos.

\section{SUMMARY}

Toxoplasma gondii the agent causing toxoplasmosis has a worldwide distribution. In the present study we attempt to determine the prevalence of toxoplasmosis in food animals and horses from farms in Jaguapitã county. IgG antibody were detected using indirect immunofluorescence. Titers higher or equal to 1:64 were considered reactive. We found prevalence rates of $24 \%$ (267) for swine, $25.8 \%$ (400) for bovine, $51.8 \%$ (228) for ovine samples, and $12.1 \%$ (173) for equine. Seropositivity increased with age in sheeps and pigs, there were no gender differences in the species studied. There was a positive and significant correlation between human and feline $(r=0.64$ $p=0.05)$, human and canine $(r=0.78 p=0.01)$, canine and swine $(r=0.96 p=0.0001)$, bovine and ovine $(r=0.82 p=0.006)$, bovine and equine $(r=0.89 p=0.001)$, and ovine and equine $(r=0.92$ $p=0.0004)$ titers. These results suggest that carnivores, herbivores, and omnivores are exposed to the same sources of transmission. Toxoplasmosis has a high prevalence on the studied population. Our results suggest that raw or rare cooked meat may an important way of transmiting toxoplasmosis to humans in this region.

Key words: seroepidemiology, seroprevalence, Toxoplasma gondii, swine, bovine, ovine, equine.

\section{INTRODUÇÃO}

O Toxoplasma gondii, agente da toxoplasmose (UGGLA , 1986), é uma protozoonose de

${ }^{1}$ Projeto financiado pela CPG-UEL /CAPES/CNPq

${ }^{2}$ Médico Veterinário do Serviço Municipal de Saúde de Jaguapitã, PR. Mestrando de Sanidade Animal, Universidade Estadual de Londrina (UEL).

${ }^{3}$ Professor, Departamento de Medicina Veterinária Preventiva, UEL, Caixa Postal 6001, 86050-970, Londrina, PR, Brasil. E-mail: italmar@npd.uel.br. Autor para correspondência.

${ }^{4}$ Acadêmicas do Curso de Medicina Veterinária, bolsistas CNPq. 
grande interesse, pois pode provocar sérios danos ao feto, tanto nos homens como nos animais (DUBEY et al , 1995b). Os únicos hospedeiros definitivos da doença são os felídeos ( FRENKEL $\boldsymbol{e t}$ al., 1970; MILLER et al., 1972), onde os gatos domésticos assumem importante papel na transmissão da doença (DUBEY et al.,1995a).

Normalmente, o $\boldsymbol{T}$. gondii parasita seu hospedeiro sem causar sinais clínicos, porém é capaz de causar uma doença severa, principalmente, quando na sua forma congênita (DUBEY, 1993). Entre os animais destinados à alimentação humana, os suínos, ovinos e caprinos são mais infectados que eqüinos e bovinos, sendo que esta última espécie, pode reduzir ou eliminar os cistos de $\boldsymbol{T}$. gondii viáveis de seus tecidos (DUBEY \& THULLIEZ, 1993).

$O$ risco de adquirir a infecção através do consumo de carnes cruas ou mal cozidas, fato comum em nossa região, é relatado por NAVARRO $\boldsymbol{e t}$ $\boldsymbol{a l}$.(1992) e VIDOTTO $\boldsymbol{e} \boldsymbol{t} \boldsymbol{a l}$.(1990). NAVARRO $\boldsymbol{e} \boldsymbol{t}$ al. (1992) demostraram esse risco, quando observaram que mais de $20 \%$ das amostras de carne suína, oriundas de um rebanho com $37 \%$ de sororeagentes, estavam infectadas com o $\boldsymbol{T}$. gondii.

O objetivo do trabalho foi avaliar a soroprevalência da toxoplasmose em suínos, bovinos, ovinos e eqüinos oriundos de propriedades rurais do município de Jaguapitã, bem como avaliar os fatores de risco associados à infecção da toxoplasmose, e a correlação entre os títulos de anticorpos obtidos interespécie e com os humanos, felinos e caninos.

\section{MATERIAL E MÉTODOS}

Fizeram parte do estudo 40 propriedades rurais, que foram sorteadas ao acaso, de um total de 506 imóveis rurais de Jaguapitã (INCRA, 1995). O município de Jaguapitã, localiza-se ao norte do Estado do Paraná, sendo formado por 10613 habitantes, com 3142 localizados na zona rural (IBGE, 1991), apresenta uma altitude de $650 \mathrm{~m}$, latitude $23^{\circ}$ sul e longitude $51^{\circ} \mathrm{W}-\mathrm{GR}$, um clima subtropical úmido mesotérmico, com média de temperatura acima de $22^{\circ} \mathrm{C}$, no verão, e abaixo de $18^{\circ} \mathrm{C}$, no inverno; extensão territorial de $463,138 \mathrm{~km}^{2}$, com uma economia voltada à produção agropecuária, e com uma população animal estimada em 37817 bovinos, 2650 suínos, 280 ovinos e 290 eqüinos (IPARDES, 1991).

A população estudada foram todos os animais encontrados nas 40 propriedades amostradas, de todas as faixas etárias, resultando em 267 amostras de soros suínos oriundas de 31 propriedades (122 machos e 145 fêmeas), 400 amostras de soros bovinos de 39 propriedades (37 machos e 363 fêmeas), 228 amostras de soros ovinos de 11 propriedades (28 machos e 200 fêmeas) e 173 amostras de soros eqüinos de 39 propriedades (131 machos e 42 fêmeas).

Com o intuito de correlacionar os títulos de anticorpos interespécies, além desses animais anteriores, fizeram parte da amostragem, 345 pessoas moradoras das 40 propriedades sorteadas (190 homens e 155 mulheres, com idades que variaram de 5 a 78 anos), 189 amostras de cães (116 machos e 73 fêmeas) e 173 amostras de felinos (75 machos e 88 fêmeas). A amostragem populacional foi obtida utilizando-se o programa Epi-Info versão 6, a partir de prevalências pré-determinadas, obtendo-se amostragens epidemiologicamente significativas.

Amostras de 2 a $10 \mathrm{ml}$ de sangue foram colhidas por punção venosa, em tubos de ensaio estéreis. No laboratório, estas amostras eram incubadas em Banho Maria a $37^{\circ} \mathrm{C}$, por duas horas, até retração do coágulo, em seguida centrifugados a $3000 \mathrm{rpm}$ durante 15 minutos. Posteriormente, os soros eram retirados e transferidos para frascos estéreis, identificados e armazenados a $-20^{\circ} \mathrm{C}$, até a realização dos exames. Todas as amostras colhidas eram acompanhadas de uma ficha epidemiológica, que contemplava os aspectos epidemiológicos relativos ao agente e à população em estudo.

Os soros foram submetidos à reação de imunofluorescência indireta (RIFI) para detecção de anticorpos anti-Toxoplasma gondii da classe $\mathrm{IgG}$, conforme técnica descrita por CAMARGO (1964), utilizando-se soro anti - IgG para cada espécie em estudo, produzido a partir de inoculações em coelhos, conjugado ao isotiocianato de fluoresceína da marca Sigma-Chemical. Em todas as reações foram incluídos soros padrões, positivo e negativo, previamente conhecidos. A leitura foi realizada em microscópio de imunofluorescência da marca NIKON. A positividade foi considerada como maior ou igual a 1:64 para suínos, bovinos, ovinos e equiinos e 1:16 nos humanos, felinos e caninos.

A magnitude da associação dos fatores de risco foi determinada pela razão de chances ( OR ), e a significância foi determinada quando $95 \%$ do intervalo de confiança não incluiu o 1 . A análise de associação entre os grupos foi testada pelo teste de Qui-quadrado $\left(\mathrm{X}^{2}\right)$, com significância estatística determinada se $p$ menor ou igual a 0,05 . Foi calculado o coeficiente de correlação para determinar a relação da distribuição dos títulos de anticorpos interespécies.

\section{RESULTADOS E DISCUSSÃO}

Com relação à população suína, demonstrou-se uma prevalência à toxoplasmose de $24 \%$, 


\begin{tabular}{|c|c|c|c|c|c|}
\hline \multirow[b]{2}{*}{ Espécie } & \multirow[b]{2}{*}{ Sexo/Idade } & \multicolumn{2}{|c|}{ RIFI } & \multirow[b]{2}{*}{ SorosTestados } & \multirow[b]{2}{*}{ Estatística } \\
\hline & & Reagentes & Não Reag. & & \\
\hline \multirow[t]{6}{*}{ Suína } & $M$ & $35(28,7 \%)$ & $87(71,3 \%)$ & $122(45,7 \%)$ & $X^{2}=2,74$ \\
\hline & $F$ & $29(20,0 \%)$ & $116(80,0 \%)$ & $145(54,3 \%)$ & $p=0,09$ \\
\hline & Total & $64(24,0 \%)$ & $203(76,0 \%)$ & 267 & \\
\hline & $<1$ & $22(16,6 \%)$ & $110(83,4 \%)$ & $132(49,4 \%)$ & $\mathrm{OR}=0,44$ \\
\hline & $\geq 1$ & $42(31,1 \%)$ & $93(68,9 \%)$ & $135(50,6 \%)$ & $0,24<\mathrm{OR}<0,83$ \\
\hline & Total & $64(23,9 \%)$ & $203(76,1 \%)$ & 267 & $X^{2}=7,64 p=0,005$ \\
\hline \multirow[t]{6}{*}{ Bovina } & $M$ & $10(27,0 \%)$ & $27(73,0 \%)$ & $37(9,3 \%)$ & \\
\hline & $F$ & $93(25,6 \%)$ & $270(74,4 \%)$ & $363(90,8 \%)$ & $X^{2}=0,03$ \\
\hline & Total & $103(25,8 \%)$ & $297(74,2 \%)$ & 400 & $p=0,85$ \\
\hline & $\leq 1$ & $23(32,9 \%)$ & $47(67,1 \%)$ & $70(17,5 \%)$ & \\
\hline & $>1$ & $80(24,2 \%)$ & $250(75,8 \%)$ & $330(82,5 \%)$ & $X^{2}=2,24$ \\
\hline & Total & $103(25,8 \%)$ & $297(74,2 \%)$ & 400 & $p=0,13$ \\
\hline \multirow[t]{7}{*}{ Ovina } & $M$ & $14(50,0 \%)$ & $14(50,0 \%)$ & $28(12,3 \%)$ & \\
\hline & $F$ & $104(52,0 \%)$ & $96(48,0 \%)$ & $200(87,7 \%)$ & $X^{2}=0,04$ \\
\hline & Total & $118(51,8 \%)$ & $110(48,2 \%)$ & 228 & $p=0,84$ \\
\hline & $\leq 1$ & $20(33,9 \%)$ & $39(66,1 \%)$ & $59(25,9 \%)$ & \\
\hline & $>1 \leq 3$ & $18(43,9 \%)$ & $23(56,1 \%)$ & $41(18,0 \%)$ & $X^{2}=14,47 p<0,0007$ \\
\hline & $>3$ & $80(62,5 \%)$ & $48(37,5 \%)$ & $128(56,1 \%)$ & \\
\hline & Total & $118(51,8 \%)$ & $110(48,2 \%)$ & 228 & \\
\hline \multirow[t]{6}{*}{ Equina } & $M$ & $16(12,2 \%)$ & $115(87,8 \%)$ & $131(75,7 \%)$ & \\
\hline & $F$ & $5(11,9 \%)$ & $37(88,1 \%)$ & $42(24,3 \%)$ & $X^{2}=0,00$ \\
\hline & Total & $21(12,1 \%)$ & $152(87,9 \%)$ & 173 & $p=0,95$ \\
\hline & $\leq 5$ & $10(16,1 \%)$ & $52(83,9 \%)$ & $62(35,8 \%)$ & \\
\hline & $>5$ & $11(9,9 \%)$ & $100(90,1 \%)$ & $111(64,2 \%)$ & $X^{2}=1,44$ \\
\hline & Total & $21(12,1 \%)$ & $152(87,9 \%)$ & 173 & $p=0,22$ \\
\hline
\end{tabular}

Sexo: $M$ - Masculino, F- Feminino

verificando-se que ocorreram diferenças estatísticas significantes nas faixas etárias, com soroprevalência aumentando com as idades. A análise da razão de chances $(\mathrm{OR})$, revelou um fator de proteção às idades mais jovens $\left(\mathrm{OR}=0,440,24<\mathrm{OR}<0,83 X^{2}=\right.$ $7,64 p=0,005)$, conforme demostra a Tabela 1; no entanto, diferenças estatísticas significativas não foram observadas em relação ao sexo (Tabela 1) e quanto à raça (Tabela 2). Com relação aos títulos de anticorpos, o maior título foi de 1:8192 (1,6\%), e os mais freqüentes $1: 64(56,3 \%)$ e $1: 256(32,8 \%)$, que podem ser observados na Tabela 3 , bem como que $92,2 \%$ dos títulos encontravam-se entre 1:64 e 1:1024, o que pode ser sugestivo de uma infecção latente (CAMARGO, 1975).

No estudo da amostragem suína, fizeram parte 31 propriedades, sendo que em apenas três, os animais eram criados em granjas (recebiam ração produzida na propriedade, piso cimentado, e animais permanentemente fechados), as demais, consistiam de criações de subsistência, com instalações rudimentares (cercados de madeira), normalmente com poucos animais, e que permaneciam em contato direto com o solo, com alimentação variada, desde cereais (milho), sobras de alimentação humana e frangos mortos de granjas.

VIDOTTO et al.(1990), estudando a prevalência da toxoplasmose em granjas suínas da região, constituídas na sua maioria de animais confinados de raças especializadas, exibiram 37,84\% de soropositivos, sem contudo, observarem diferenças em relação às faixas etárias. Esperava-se, que a soroprevalência suína no presente estudo, fosse maior, devido ao baixo nível de manejo e instalações 
Tabela 2 - Detecção de anticorpos anti-T. gondii, através da reação de imunofluorescência indireta-IgG (RIFI), em soros de suínos e bovinos, correlacionados ao fator raça, no município de Jaguapitã (zona rural), Paraná, Brasil, 1998.

\begin{tabular}{|c|c|c|c|c|c|}
\hline \multirow[b]{2}{*}{ Espécie } & \multirow[b]{2}{*}{ Raça } & \multicolumn{2}{|c|}{$R I F I$} & \multirow[b]{2}{*}{$\begin{array}{c}\text { Total Soros } \\
\text { Testados }\end{array}$} & \multirow[b]{2}{*}{ Estatística } \\
\hline & & Reagentes & Não Reagentes & & \\
\hline \multirow[t]{3}{*}{ Suína } & Não Especializados & $28(21,5 \%)$ & $102(78,5 \%)$ & $130(48,7 \%)$ & \multirow{3}{*}{$X^{2}=0,82 \mathrm{p}=0,36$} \\
\hline & Especializados & $36(26,3 \%)$ & $101(73,7 \%)$ & $137(51,3 \%)$ & \\
\hline & Total & $64(24 \%)$ & $203(76 \%)$ & 267 & \\
\hline \multirow[t]{4}{*}{ Bovina } & $\begin{array}{l}\text { Holandesa } \\
\text { (Bos taurus) }\end{array}$ & $13(40,6 \%)$ & $19(59,4 \%)$ & $32(8,0 \%)$ & \multirow{3}{*}{$\begin{array}{c}\text { OR }=2,11 \\
(0,94<\mathrm{OR}<4,71) \\
X^{2}=4,03 \mathrm{p}=0,04\end{array}$} \\
\hline & & & & & \\
\hline & $\begin{array}{c}\text { Mestiços } \\
\text { (B.taurus x B. Indi- } \\
\text { cus) }\end{array}$ & $90(24,5 \%)$ & $278(75,5 \%)$ & $368(92,0 \%)$ & \\
\hline & Total & $103(25,8 \%)$ & $297(74,3 \%)$ & 400 & \\
\hline
\end{tabular}

Tabela 3 - Recíproca dos títulos de anticorpos anti-T. gondii, através da reação de imunofluorescência indireta-IgG (RIFI), em soros de suínos, bovinos, ovinos, eqüinos, humanos, felinos e caninos do meios rural, no município de Jaguapitã, Paraná, Brasil, 1998.

\begin{tabular}{|c|c|c|c|c|c|c|c|c|c|c|}
\hline \multirow[b]{2}{*}{ Espécie } & \multicolumn{9}{|c|}{ Títulos de Anticorpos à RIFI-IgG } & \multirow[b]{2}{*}{ Total } \\
\hline & 16 & 64 & 256 & 1024 & 4096 & 8192 & 16384 & 32768 & 65536 & \\
\hline Suína & $44 *$ & $\begin{array}{c}36 \\
56,3 \%\end{array}$ & $\begin{array}{c}21 \\
32,8 \%\end{array}$ & $\begin{array}{c}2 \\
3,1 \%\end{array}$ & $\begin{array}{c}4 \\
6,2 \%\end{array}$ & $\begin{array}{c}1 \\
1,6 \%\end{array}$ & 0 & 0 & 0 & 64 \\
\hline Bovina & $113^{*}$ & $\begin{array}{c}77 \\
74,7 \%\end{array}$ & $\begin{array}{c}21 \\
20,4 \%\end{array}$ & $\begin{array}{c}2 \\
2,0 \%\end{array}$ & $\begin{array}{c}3 \\
2,9 \%\end{array}$ & 0 & 0 & 0 & 0 & 103 \\
\hline Ovina & $62 *$ & $\begin{array}{c}22 \\
18,6 \%\end{array}$ & $\begin{array}{c}17 \\
14,4 \%\end{array}$ & $\begin{array}{c}20 \\
17,0 \%\end{array}$ & $\begin{array}{c}15 \\
12,7 \%\end{array}$ & $\begin{array}{c}27 \\
22,9 \%\end{array}$ & $\begin{array}{c}6 \\
5,0 \%\end{array}$ & $\begin{array}{c}8 \\
6,8 \%\end{array}$ & $\begin{array}{c}3 \\
2,6 \%\end{array}$ & 118 \\
\hline Eqüina & $65^{*}$ & $\begin{array}{c}12 \\
57,1 \%\end{array}$ & $\begin{array}{c}9 \\
42,9 \%\end{array}$ & 0 & 0 & 0 & 0 & 0 & 0 & 21 \\
\hline Humana & $\begin{array}{c}38 \\
16,7 \%\end{array}$ & $\begin{array}{c}36 \\
15,9 \%\end{array}$ & $\begin{array}{c}65 \\
28,6 \%\end{array}$ & $\begin{array}{c}44 \\
19,4 \%\end{array}$ & $\begin{array}{c}30 \\
13,2 \%\end{array}$ & $\begin{array}{c}5 \\
2,2 \%\end{array}$ & $\begin{array}{c}4 \\
1,8 \%\end{array}$ & $\begin{array}{c}3 \\
1,3 \%\end{array}$ & $\begin{array}{c}2 \\
0,9 \%\end{array}$ & 227 \\
\hline Felina & $\begin{array}{c}12 \\
10,1 \%\end{array}$ & $\begin{array}{c}17 \\
14,3 \%\end{array}$ & $\begin{array}{c}26 \\
21,8 \%\end{array}$ & $\begin{array}{c}20 \\
16,9 \%\end{array}$ & $\begin{array}{c}34 \\
28,6 \%\end{array}$ & $\begin{array}{c}2 \\
1,7 \%\end{array}$ & $\begin{array}{c}6 \\
5,0 \%\end{array}$ & $\begin{array}{c}1 \\
0,8 \%\end{array}$ & $\begin{array}{c}1 \\
0,8 \%\end{array}$ & 119 \\
\hline Canina & $\begin{array}{c}50 \\
31,4 \%\end{array}$ & $\begin{array}{c}61 \\
38,4 \%\end{array}$ & $\begin{array}{c}35 \\
22 \%\end{array}$ & $\begin{array}{c}10 \\
6,3 \%\end{array}$ & $\begin{array}{c}3 \\
1,9 \%\end{array}$ & 0 & 0 & 0 & 0 & 159 \\
\hline
\end{tabular}

* Reações Inespecíficas

da maioria das criações, porém WEIGEL et al.(1995) descrevem que o pré-requisito para a infecção toxoplásmica, nesta espécie, é a presença dos reservatórios da doença (felinos e roedores) em contato com os animais, e as características das criações estudadas, normalmente, não apresentavam atrativo para os felinos, o que acabava caracterizando um baixo nível de contato entre as duas espécies. Outro fator, que pode ter favorecido a prevalência é relatado por VIDOTTO $\boldsymbol{e}$ t al.(1990) e WENTZ $\boldsymbol{e}$ t al.(1988) no qual a utilização da ração fabricada na própria propriedade, poderia aumentar o risco de 
infecção nas granjas, pois estas atraem roedores e, conseqüentemente os felinos que as contaminam.

WENTZ et al.(1988), avaliando suínos de pedigree, criados semi-intensivamente em Santa Catarina, exibiram pela hemaglutinação indireta uma prevalência para a toxoplasmose de $1,16 \%$ em animais oriundos de propriedades com maiores cuidados de limpeza e desinfecção, uso de rações industrializadas e maiores cuidados com roedores. ASSADI-RAD et al.(1995) verificaram que a infecção toxoplásmica em suínos estava associada principalmente ao manejo extensivo, presença de gatos na propriedade, tamanho da propriedade e método utilizado para controle de roedores. DUBEY et al.(1995b) descreveram que o solo e os alimentos são as duas vias diretas de infecção para os suínos, e demostraram uma prevalência de $15,1 \%$ em suínos de granjas, e 2,3\% em animais destinados ao abate.

Os bovinos apresentaram uma soroprevalência de 25,8\% (Tabela 1) menor que a observada por MARANA et al.(1995), na mesma macro região, onde verificaram uma soroprevalência de $48,51 \%$, e isto pode estar ligado ao fato de que a grande maioria dos animais amostrados no presente estudo foram animais mestiços e adultos. Não foram observadas diferenças estatísticas significativas com relação às faixas etárias e sexo (Tabela 1), embora tenha-se verificado uma soropositividade menor nos animais adultos. DUBEY (1996) relata que bovinos podem soronegativar à toxoplasmose dois anos após inoculação experimental. Animais da raça Holandesa tiveram um risco 2,11 vezes maior de soropositividade à toxoplasmose em relação aos animais Mestiços (Tabela 2), resultados que vêm ao encontro do observado por OLIVEIRA (1997), que descreve uma maior sensibilidade dos animais Bos taurus, em relação ao B. indicus e Bubalis bubalis. O maior título observado foi de 1:4096 (2,9\%) e os mais freqüentes foram 1:64 (74,7\%) e 1:256 (20,4\%), resultados que se assemelham aos observados por MARANA et al.(1995). Cerca de 97\% dos bovinos apresentaram títulos menores ou iguais a 1:1024, o que é sugestivo de uma fase de infecção latente da doença, com presença de cistos teciduais. DUBEY $\&$ THULLIEZ (1993) demostraram que cistos teciduais podem permanecer por períodos de até 1191 dias, nos bovinos.

As amostras de soros ovinos revelaram uma prevalência de $51,8 \%$, com soropositividade, aumentando com a idade e sem diferença estatística significante com relação ao sexo (Tabela 1). O maior título encontrado foi de 1:65536 (2,6\%), e os títulos mais frequientes foram 1:8192 (22,9\%) e 1:64 $(18,6 \%)$, conforme Tabela 3 . Verificou-se que $50 \%$ dos ovinos sororeagentes apresentaram títulos maiores ou iguais a 1:4096, e podem estar relacionados a infecções recentes (SHKAP et al., 1992). Resultados semelhantes foram observados por FREIRE et al. (1995), com prevalência de 47,83\%, também com maior título de 1: 65536, diferenciando-se quando não relatam aumento da soropositividade com a idade. Resultados discrepantes são mencionados por ZONTA et al.(1987), no Rio Grande do Sul, onde verificaram soroprevalência entre $18 \%$ na hemaglutinação indireta, correlacionando a baixa prevalência, ao sistema de criação extensivo.

$\mathrm{Na}$ população eqüina, verificou-se soroprevalência de $12,1 \%$ e os título encontrados foram de 1:64 (57,1\%) e 1:256 (42,9\%), podendo-se caracterizá-los sugestivos de uma infecção latente (Tabela 3). Nenhuma diferença estatística significativa foi verificada entre o sexo e as idades (Tabela 1). Resultados semelhantes foram observados por KANO et al.(1997), estudando eqüinos de matadouros, quando consideraram títulos positivos à RIFI$\mathrm{IgG}$, maiores ou iguais a $1: 16$, observaram $32,12 \%$ de reagentes, sendo que aqueles reagentes a 1:16 $(54,6 \%), \quad 1: 64$ (19\%), $1: 256(12,43 \%), \quad 1: 1024$ $(1,08 \%)$ e $1: 4096(2,7 \%)$.

As correlações dos títulos de anticorpos pela RIFI-IgG, entre as espécies estudadas, foram obtidas através da comparação da recíproca dos títulos encontrados, conforme demonstra a Tabela 3. Observou-se uma elevada prevalência à toxoplasmose na sorologia das espécies humana $(65,8 \%)$, felina $(73 \%)$ e canina $(84,1 \%)$, as quais foram incluídas no estudo de correlação. Na Tabela 4, pode-se observar as correlações positivas e significativas entre os títulos de anticorpos das espécies estudadas, sendo que epidemiologicamente apresentaram importância, as correlações exibidas entre as espécies humanacanina, humana-felina, canina-suína, bovina-ovina, bovina-eqüina e ovina-eqüina, o que pode estar relacionada ao fato dessas espécies estarem compartilhando as mesmas vias de transmissão. Entre o homem e o cão, supõe-se que a fonte de infecção comum seja a alimentação. Em relação à correlação humana e felina, a presença dos gatos é provavelmente a causa dessa correlação positiva, não pelo contato direto, mais sim devido a esses animais eliminarem milhões de oocistos que contaminam o meio ambiente. Chama a atenção o fato da correlação entre a população humana ter ocorrido apenas com as duas espécies de maior convívio, ou seja, o cão e o gato. Em relação aos herbívoros, as pastagens seriam de importância para a contaminação, o que é demonstrada pela correlação alta e significativa entre essas espécies e entre os ovinos-eqüinos, uma vez que estes animais possuem o mesmo hábito 
Tabela 4 - Resultados das correlações positivas e significantivas dos títulos de anticorpos anti- $T$. gondii da classe IgG, através da reação de imunofluorescência indireta-IgG, entre as espécies humana, felina, canina, suína, bovina, ovina e eqüina oriundas de propriedades rurais do município de Jaguapitã, Paraná, Brasil, 1998.

\begin{tabular}{|c|c|c|c|c|c|c|c|}
\hline Espécies & Humanos & Cães & Gatos & Bovinos & Ovinos & Equinos & Suínos \\
\hline Humanos & $\begin{array}{c}r=1 \\
0,0\end{array}$ & $\begin{array}{c}r=0,64 \\
0,05^{*}\end{array}$ & $\begin{array}{c}r=0,78 \\
0.01\end{array}$ & ns & $\mathrm{ns}$ & ns & $\mathrm{ns}$ \\
\hline Cães & $\begin{array}{c}\mathrm{r}=0,64 \\
0,05\end{array}$ & $\begin{array}{c}r=1 \\
0,0\end{array}$ & ns & $\begin{array}{c}r=0,89 \\
0,001\end{array}$ & ns & $\begin{array}{c}r=0,66 \\
0,04\end{array}$ & $\begin{array}{c}r=0,96 \\
0,0001\end{array}$ \\
\hline Gatos & $\begin{array}{c}r=0,78 \\
0,01\end{array}$ & $\mathrm{~ns}$ & $\begin{array}{l}r=1 \\
0,0\end{array}$ & ns & $\mathrm{ns}$ & $\mathrm{ns}$ & $\mathrm{ns}$ \\
\hline Bovinos & ns & $\begin{array}{c}r=0,89 \\
0,001\end{array}$ & $\mathrm{~ns}$ & $\begin{array}{c}r=1 \\
0,0\end{array}$ & $\begin{array}{c}r=0,82 \\
0,006\end{array}$ & $\begin{array}{c}r=0,89 \\
0,001\end{array}$ & $\begin{array}{c}r=0.96 \\
0,0001\end{array}$ \\
\hline Ovinos & ns & ns & $\mathrm{ns}$ & $\begin{array}{c}r=0,82 \\
0,006\end{array}$ & $\begin{array}{c}\mathrm{r}=1 \\
0,0\end{array}$ & $\begin{array}{c}r=0,92 \\
0,0004\end{array}$ & $\begin{array}{c}\mathrm{r}=0,75 \\
0,01\end{array}$ \\
\hline Eqüinos & ns & $\begin{array}{c}r=0,66 \\
0,04\end{array}$ & ns & $\begin{array}{c}r=0,89 \\
0,001\end{array}$ & $\begin{array}{c}r=0,92 \\
0,0004\end{array}$ & $\begin{array}{c}r=1 \\
0,0\end{array}$ & $\begin{array}{c}r=0,83 \\
0,005\end{array}$ \\
\hline Suínos & $\mathrm{ns}$ & $\begin{array}{c}r=0,96 \\
0,0001\end{array}$ & ns & $\begin{array}{c}r=0,96 \\
0,0001\end{array}$ & $\begin{array}{c}r=0,75 \\
0,01\end{array}$ & $\begin{array}{c}r=0,83 \\
0,005\end{array}$ & $\begin{array}{c}r=1 \\
0,0\end{array}$ \\
\hline
\end{tabular}

de pastejo. A forte correlação entre suínos e caninos, com $p$ altamente significativo, pode estar ligado à alimentação, já que grande parte dessas duas espécies recebiam sobras de alimentação humana.

\section{CONCLUSÃO}

A elevada prevalência da toxoplasmose na região e o alto risco da carne como via de transmissão para a população humana, quando esta é ingerida crua ou mal cozida, já que a maioria dos animais estudados são destinados ao consumo humano e apresentavam títulos característicos de uma possível infecção latente. Pode-se observar, com o estudo de correlação, que as espécies hominívoras, carnívoras e herbívoras estariam expostas a fontes comuns de transmissão.

\section{REFERÊNCIAS BIBLIOGRÁFICAS}

ASSADI-RAD, A.M., NEW, J.C., PATTON, S. Risk factors association with transmision of Toxoplasma gondii to sows kept in different management systems in Tennessee. Veterinary Parasitology, v. 57, p. 289-297, 1995.

CAMARGO, M.E. Improved tchnique of indirect imunofluorescence for serological diagnosis of toxoplasmosis. Rev Inst Med Trop de São Paulo, v. 6, n. 3, p. 117-18, 1964.

CAMARGO, M.E. Diagnóstico sorológico da toxoplasmose na gravidez . Rev Ass Med Bras, v. 21, n. 11, p. 341-346, 1975.
DUBEY, J.P. Toxoplasma, Neospora, Sarcocystis and other tissue cyst- forming of human and aniamls. In: KRIER, JP . Parasitic Protozoa. 2.ed. San Diego:Academic Press, 1993. p. 1-157.

DUBEY, J.P. Strategies to reduce transmission of Toxoplasma gondii to animals and humans . Veterinary Parasitology, v. 64, p. 65-70, 1996.

DUBEY, J.P., LAPPIN, M.R., THULLIEZ, P. Long term antibody responses of cat fed Toxoplasma gondii tissue cysts. J Parasitology, v. 81, n. 6, p. 887-893, 1995a.

DUBEY, J.P., THULLIEZ, P. Persistence of tissue cysts in edible tissues of cattle fed gondii oocysts. Am J Vet Res, v. 54, n. 2, p. 270-273, Feb. 1993.

DUBEY, J.P., WEIGEL, R.M., SIEGEL, A.M. et al. Sources and reservoirs of Toxoplasma gondii infection on 47 swine farms in Illinois. J Parasitol, v. 81, n. 5, p. 723-729, 1995b.

FREIRE, R.L., GIRALDI, N., VIDOTTO,O. et al. Levantamento soroepidemiológico da toxoplasmose em ovinos na região de Londrina, Paraná. Arq Bras Med Vet Zoot, v. 47, n. 4, p. 609-612, 1995.

FRENKEL, J.K., DUBEY, J.P., MILLER, N.L. Toxoplasma gondii in cats fecal stages identified as coccidian oocysts. Science, v. 167, p. 893-896, 1970.

FUNDAÇÃO INSTITUTO BRASILEIRO DE GEOGRAFIA E ESTATÍSTICA (IBGE). Sinapse preliminar do censo demográfico: resultados do universo relativos às características da população e dos domicílios, Paraná, $n$. 20, Rio de Janeiro : IBGE, 1991. 
INSTITUTO NACIONAL DE COLONIZAÇÃO E REFORMA AGRÁRIA (INCRA). Relação de Certificados de Cadastro e Notificações de Imóveis Rurais Emitidos, 714151Jaguapitã, Paraná : INCRA, 1995.

INSTITUTO PARANAENSE DE DESENVOLVIMENTO ECONÔMICO E SOCIAL (IPARDES). Caderno de Estatísticas Municipal. Jaguapitã : IPARDES, 1991.

KANO, F.S., FREIRE, R.L., MITSUKA, R. et al. Ocorrência e anticorpos anti- Toxoplasma gondii em eqüinos na região de Londrina. Rev Bras Parasit Vet, v. 6, n. 2, p. 34 , Ago. 1997.

MARANA, E.R.M., VENTURINI, A.C.H., FREIRE, R.L. $\boldsymbol{e}$ t $\boldsymbol{a}$ l. Ocorrência de anticorpos anti-Toxoplasma gondii em rebanhos de bovinos de leite do norte do Paraná - Brasil. Semina: Ciências Agrárias, v. 16, n. 1, p. 40-42, Mar. 1995.

MILLER, N.L., FRENKEL, J.K., DUBEY, J.P. Oral infections with Toxoplasma cysts and oocysts in felines, other mammals and birds. J Parasitology, v. 58, p. 928-937, 1972.

NAVARRO, I.T., VIDOTTO, O., GIRALDI, N. et al. Estudo da resistência do Toxoplasma gondii ao efeito do cloreto de sódio e condimentos em linguiça frescal de suínos. Boletin Sanit Panam, v. 112, p. 138-143, 1992.

OLIVEIRA, F.C.R. Infecção Experimental de Bos indicus, Bos taurus e Bubalis bubalis com oocistos de Toxoplasma gondii. Estudo Comparativo. Jaboticabal - SP, 83 p.
Dissertação (Mestrado) - Faculdade de Ciências Agrárias e Veterinária Campus de Jaboticabal, Universidade Estadual de São Paulo, 1997.

SHKAP, V., PIPANO, E., MARCUS, S. et al. The prevalence of Toxoplasma gondii antibodies and sheep and cattle in Israel. Isr J Vet Med, v. 47, p. 100-102, 1992.

UGGLA, A. Toxoplasma gondii in farm animals : some immunodiagnostic methods and their potential use. Uppsala: Merkantil-Tryckeriet, 1986. p. 1-56.

VIDOTTO, O., NAVARRO, I.T., GIRALDI, I.T. et al. Estudos epidemiológicos da toxoplasmose em suínos da região de Londrina - PR. Semina, v. 11, n. 1, p. 53-59, 1990.

WEIGEL, R.M., DUBEY, J.P., SIEGEL, A.M. et al. Risk factors for transmission of Toxoplasma gondii on swine farms in Illinois. J Parasitol, v. 81, n. 5, p. 736-741, 1995.

WENTZ, I., SOBESTIANSKY, J., CHAPLIN, E. Prevalência de anticorpos para toxoplasmose em soros de suínos de pedigree em Santa Catarina. Concórdia : Empresa Brasileira de Pesquisa Agropecuária, 1988. 3p. Comunicado Técnico, 130.

ZONTA, J.C., ARAÚJO, F.A.P., STOBBE, N.S. $\boldsymbol{e} \boldsymbol{t} \boldsymbol{a l}$. Prevalência de anticorpos toxoplásmicos em ovinos de Marau e de Uruguaiana, RS. Arq Fac Vet-UFRGS, v. 15-16, p. 59$61,1987 / 8$.

Ciência Rural, v. 29, n. 1, 1999. 